\title{
Bacteriophage of Haemophilus influenzae
}

\section{Morphology, DNA Homology, and Immunity Properties of HP1c1, S2, and the Defective Bacteriophage from Strain $R d$}

\author{
MAXON E. BOLING, DAVID P. ALLISON, AND JANE K. SETLOW \\ Biology Division, Oak Ridge National Laboratory, Oak Ridge, Tennessee $\$ 7830$
}

Received for publication 20 November 1972

\begin{abstract}
The phages HP1c1 and S2 and a defective phage of Haemophilus influenzae have been compared. The morphology of the phages and the mol wt of their DNAs are similar, although the defective phage appears to have a different tail plate region. Electron microscope observation indicates that the defective phage does not attach to the cell surface, and its DNA appears to lack cohesive ends. The homology of the DNAs of the phages has been measured by hydridization. DNA from the defective phage shows little or no homology with the other phage DNAs. HP1c1 and S2 DNAs show a high level of homology. Each of these phages can form plaques on lawns of the lysogen of the other phage but at reduced plating efficiencies, suggesting that the two phages have related but not identical immunity systems.
\end{abstract}

Three independently isolated bacteriophages of Haemophilus influenzae have been reported: HP1 and the mutants $c 1$ and $c 2$ derived from HP1 (9), S2 (J. W. Bendler, Ph.D. thesis, The Johns Hopkins Univ., Baltimore, Md., 1968), and N3 (10). The phage N3 is morphologically unrelated to the other two phages; it has a longer tail and no contractile sheath. The host of N3 is strain 9, whereas the host for the other two phages is strain $R d$. In addition to these phages, electron microscopy has provided evidence for the existence of defective phages induced by UV irradiation of strains $R b$ and $R d$ (12). In crude lysates these phages appeared to have empty heads and thus presumably did not contain DNA. Purification of defective phage from strain $R d$ results in virus particles that do contain DNA. This paper presents comparisons of morphology, DNA, and immunity characteristics of the defective phage and the temperate phages of strain $R d$ (HP1c1 and S2).

\section{MATERIALS AND METHODS}

Microorganisms. $H$. influenzae strain $R d$ was originally obtained from R. M. Herriott. The UVresistant mutant of strain $R d, \mathrm{BC} 200$ (1), was supplied by B. J. Barnhart. The phages HPlcl and S2 were obtained from W. Harm and J. W. Bendler, respectively.

Growth of cells and phage, labeling of phage and cell DNA with $\left[{ }^{3} H\right]$ thymidine, and purification of cell DNA. These procedures have been described previously $(5,11)$. HP1c1 or S2 phage was plated with about $8 \times 10^{7}$ lysogenic cells in $2 \mathrm{ml}$ of $0.3 \%$ soft top agar instead of the usual $2.5 \mathrm{ml}$ of $0.6 \%$ agar. Under these conditions the plaques formed with one phage on lysogens of the other phage were visible enough to count.

Preparation of phage DNA. Phages were purified and DNA was extracted as previously described (5). In some cases, bacterial DNA present in the crude lysates was degraded with $100 \mu \mathrm{g}$ of pancreatic DNase per $\mathrm{ml}$ in the presence of $0.5 \mathrm{~mm} \mathrm{MgSO}_{4}$ before purification of the phage, or the phage preparation was treated with DNase after being banded in $\mathrm{CsCl}$. The amount of $\mathrm{HP1} 1$ or S2 DNA was calculated from optical density (OD) measurements. For hybridization, phage DNA was extracted with phenol, followed by exhaustive dialysis against distilled water to remove the phenol.

Electron microscopy. Droplets of phage suspension or mixtures of bacteria and phage were pipetted onto carbon-coated parlodion films supported on 400-mesh copper grids and allowed to adsorb for $2 \mathrm{~min}$. Preparations were rinsed by touching the sample meniscus to water, and the excess water was withdrawn by touching the grid to filter paper. Samples were negatively stained by placing a drop of $1 \%$ aqueous uranyl acetate on the grid and immediately withdrawing the excess stain with filter paper (7). Electron micrographs were made with a Siemens Elmiskop I electron microscope at magnifications calibrated with a Fullam $(54,864$ lines/inch; 21,600 lines/cm) diffraction grating replica. Measurements were made from projections of the calibrated electron micrographs.

Defective phage DNA was prepared for electron microscopy as previously described (5).

Velocity sedimentation of DNA. Neutral sucrose gradients (5 to $20 \%$ in $0.6 \mathrm{M} \mathrm{NaCl}$ ) were layered with 0.1 to $0.2 \mathrm{ml}$ of DNA in $0.07 \mathrm{~m}$ phos- 
phate buffer, $\mathrm{pH} \mathrm{7,} \mathrm{and} \mathrm{centrifuged} \mathrm{for} 100 \mathrm{~min}$ at $40,000 \mathrm{rpm}$ in an SW50.1 rotor. Gradient fractions were processed and assayed for radioactivity by the paper strip method of Carrier and Setlow (8).

DNA-DNA hybridization. Homology between the DNAs was measured by hybridization on membrane filters. The methods have been described in detail (4).

\section{RESULTS}

Isolation of DNA-containing defective phage. Lysates of $H$. influenzae strain $R d$ induced with mitomycin $\mathrm{C}(0.33 \mu \mathrm{g} / \mathrm{ml})$, filtered and centrifuged at high speed, show a phage pellet, which may subsequently be banded in $\mathrm{CsCl}$ as described earlier for phage $\mathrm{HP} 1 c 1$ (5). The band appears in approximately the same position as that of $\mathrm{HP} 1 c 1$, although the yield of defective phage is considerably smaller. A similar treatment of strain $\mathrm{BC} 200$ results in no visible phage pellet, suggesting that this strain does not carry the defective prophage present in strain $R d$, or that the defective prophage is altered so that it is no longer inducible by mitomycin C. It has been observed that another UV-resistant variant of strain $R d$, which like BC200 (2) does not exhibit lysis after UV irradiation, nevertheless contains occasional particles that appear to be phage after UV irradiation (12). Thus we cannot conclude from the lack of visible phage pellet that strain $\mathrm{BC} 200$ is cured of its defective phage.

The fact that the defective phage from strain $R d$ bands in $\mathrm{CsCl}$ at a position similar to that of HP1c1 indicates that it contains DNA. This conclusion is substantiated by the velocity sedimentation data presented below for thymidine-containing material extracted from defective phage.

Morphology of defective phage, HPIcl, and S2. Examination of crude lysates of defective lysogens showed primarily separate heads and tails. The rare intact particles were concentrated by banding in $\mathrm{CsCl}$. Electron micrographs of the intact defective phage, HP1c1, and S2 are shown in Fig. 1. All exhibit similar morphologies, hexagonal heads, and elongated tails with repeating crosswise stripes. The tails consist of contractile sheaths covering internal cores. The tails of HP1c1 and S2 terminate in well-defined tail plates with extended tail fibers, but the defective phage appears to have a poorly defined plate and rudimentary tail fibers.

Structural measurements made on the three phages are presented in Table 1 . The dimensions
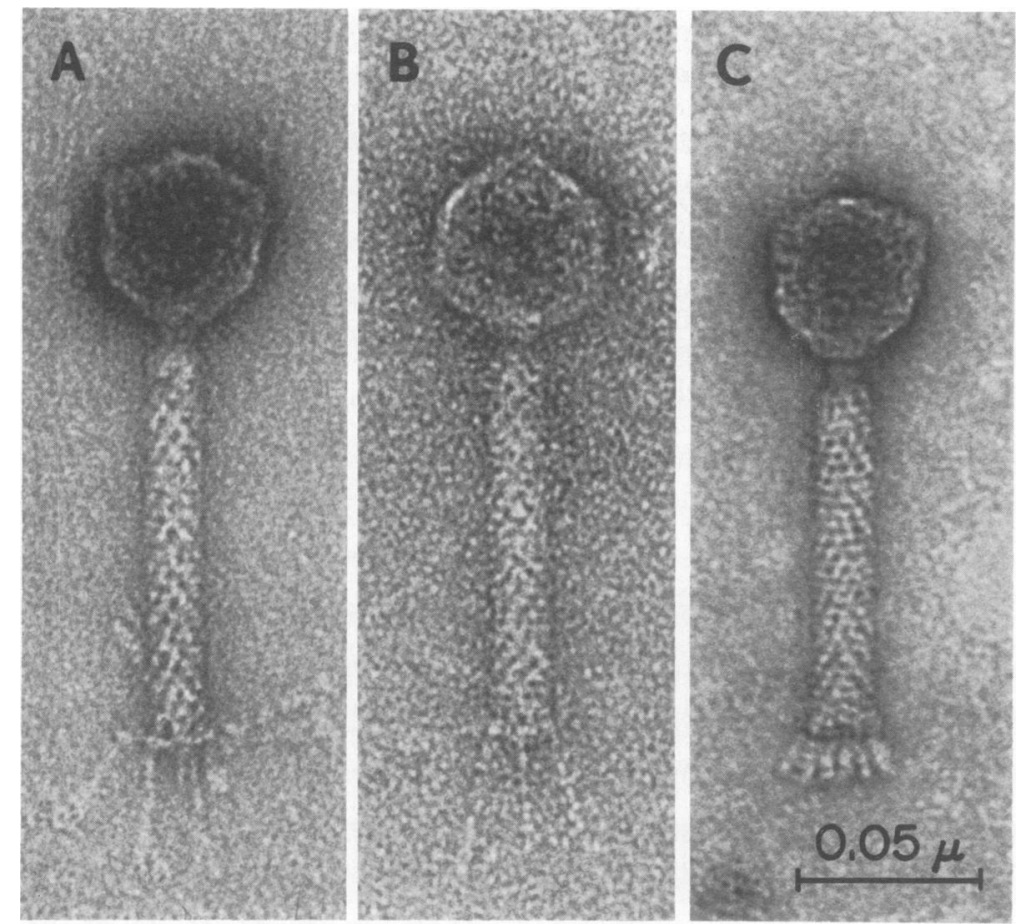

FIG. 1. Electron micrographs of phages HP1c1 (A), S\& (B), and defective phage from strain Rd $(C)$, negatively stained with uranyl acetate. $\times \$ 50,000$. 
TABLE 1. Dimensions of phages HP1c1, S2, and defective phage

\begin{tabular}{l|c|c|c|c|c}
\hline \multirow{2}{*}{ Phage } & \multirow{2}{*}{$\begin{array}{c}\text { No. of phages } \\
\text { measured }\end{array}$} & \multicolumn{2}{|c|}{ Head } & \multicolumn{2}{|c}{ Tail } \\
\cline { 2 - 3 } & & Length (nm) & Width (nm) & Length (nm) & Width (nm) \\
\cline { 5 - 6 } & 35 & $52( \pm 4)$ & $50( \pm 5)$ & $122( \pm 6)$ & $19( \pm 2)$ \\
HP1c1 & 29 & $49( \pm 4)$ & $46( \pm 3)$ & $117( \pm 3)$ & $19( \pm 0.5)$ \\
S2 & 11 & $48( \pm 3)$ & $45( \pm 3)$ & $101( \pm 7)$ & $18( \pm 2)$ \\
Defective & 11 &
\end{tabular}

of HP1c1 and S2 are approximately the same within experimental error. The defective phage appears to be nearly identical to HP1c1 and S2, except for a difference in tail length.

Preliminary measurements of phage HP1c1 reported earlier (9) identified a hexagonal head $60 \mathrm{~nm}$ in width and a tail 20 by $120 \mathrm{~nm}$, but our measurements are about $50 \mathrm{~nm}$ for the head and 19 by $122 \mathrm{~nm}$ for the tail. These observed differences may be due to different methods of preparation. UV-inducible phagelike particles have been observed previously (12) in thin sections of lysates of strain $R d$ with head widths of $64 \mathrm{~nm}$ and tail dimensions of 110 by $12 \mathrm{~nm}$. These particles may correspond to the inducible defective phage we have described (head approximately $45 \mathrm{~nm}$ and tail 101 by $18 \mathrm{~nm}$ ).

Lack of attachment of defective phage. Two methods were used to investigate whether or not the defective phage can attach to cells. The presence of an inducible defective phage can be detected by treating a culture with mitomycin $\mathrm{C}$ and measuring the OD decrease, as shown in Fig. 2. Strain Rd begins to lyse about $2 \mathrm{~h}$ after treatment, but strain BC200 shows no evidence of lysis. Such OD measurements were used to determine whether BC200 cells could be lysogenized by inducible defective phage as follows. A fresh preparation of concentrated defective phage was added to exponentially growing cells of strain $\mathrm{BC} 200$ at $10^{\circ}$ phage $/ \mathrm{ml}$, and after incubation at $37 \mathrm{C}$ for $30 \mathrm{~min}$ the mixture was plated. There was no measurable lethal effect of the exposure to the phage. Colonies were picked, grown up, and treated with mitomycin C. None of the 120 clones tested showed evidence of lysis at 2 and $3 \mathrm{~h}$ after treatment with mitomycin C. We estimated from similar experiments with phage HP1c1 that at least $10 \%$ of the cells might be expected to become lysogenized under these conditions. Since OD did not drop in any of the cultures, it was tentatively concluded that the defective phages either do not attach to strain BC200 or do not inject their DNA. Electron microscopic observation of BC200 as well as $R d$ cells exposed to defective phage or to HP1c1 showed that

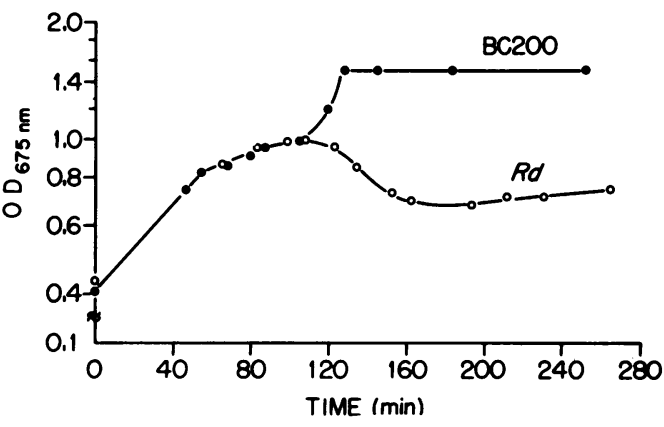

Frg. 2. Optical density at $675 \mathrm{~nm}$ of $\boldsymbol{H}$. influenzae strains $R d$ and BC200 treated with $0.35 \mu g$ of mitomycin $C$ per ml at time zero and incubated in gronth medium for the times shown. The mitomycin $C$ itself inhibited the growth of both cultures to some extent. The increase in $O D_{675}$ in strain BC200 at 110 min, after a leveling off, was a reproducible phenomenon and was also seen in both cultures grown without mitomycin.

HP1c1 phages attached to cells by their tails, whereas the defective phage did not attach to either strain.

Size and cohesive ends of phage DNA. Sedimentation profiles of labeled DNA extracted from HP1c1, S2, and the defective phage are shown in Fig. 3. The position of the peaks of radioactivity indicate that the mol wt of the DNA from the three phages are approximately the same (about $2 \times 10^{7}$ ). The defective phage DNA sediments in a single sharp peak, whereas in HP1c1 and S2 preparations there is also more rapidly sedimenting DNA, as indicated by smaller peaks to the left of the major peaks. It was previously shown that the rapidly sedimenting DNA from HP1c1 consisted of concatamers of single genomes (3, 5; J. W. Bendler, Ph.D. thesis). The lack of measurable amounts of concatamers of defective phage DNA suggests that either this DNA lacks cohesive ends or the cohesive ends are too short to hold two or more DNA molecules together during sedimentation.

Circular monomers and dimers of HP1c1 DNA are formed when the DNA is heated to $75 \mathrm{C}$ in $0.6 \mathrm{M} \mathrm{NaCl}$ and cooled slowly (5). When DNA 

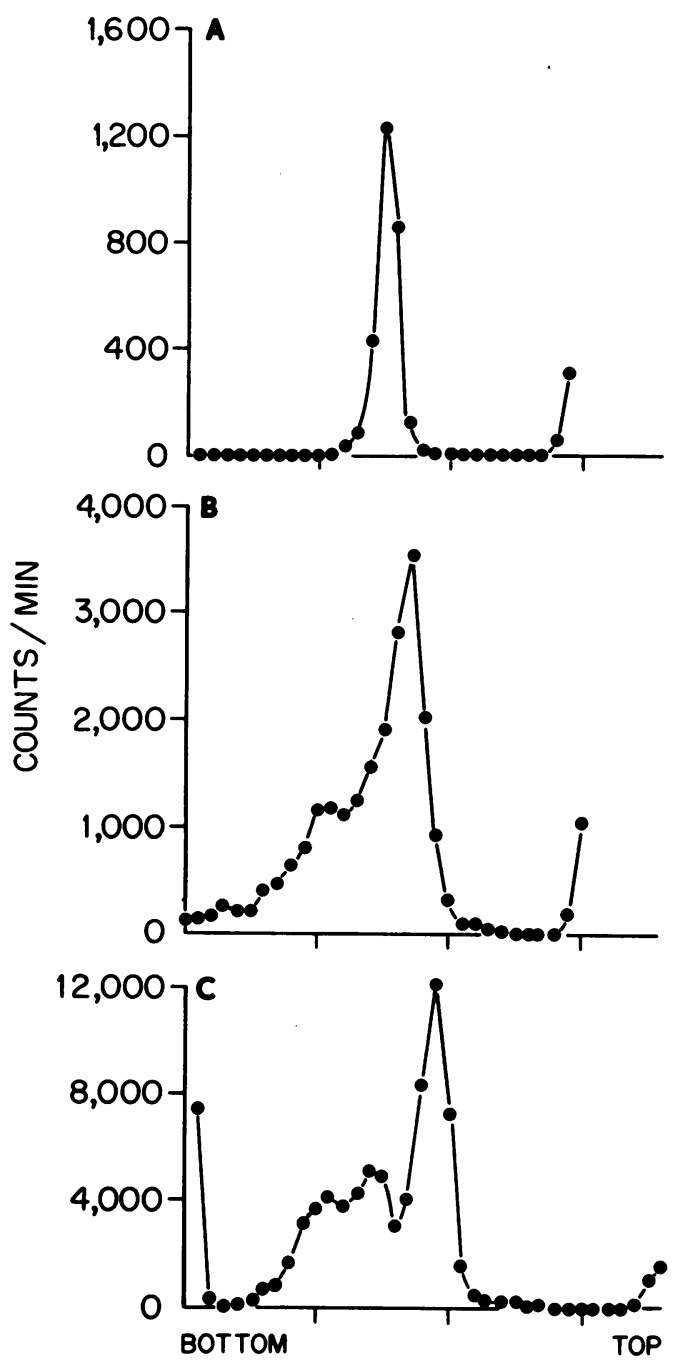

FIg. 3. Sedimentation profiles of DNAs from the defective phage $(A), H P 1 c 1(B)$, and $S \&(C)$ in neutral sucrose gradients. The number of fractions was not the same in the three gradients.

from defective phage was subjected to this treatment, no circles were observed by electron microscopy among 200 DNA molecules, again indicating that DNA from defective phage lacks cohesive ends.

DNA homology. Table 2 presents the results of hybridization experiments between the DNAs of HP1c1 and S2. These experiments were done in two ways. Disks containing unlabeled DNA of HP1c1 or S2 were incubated with sonically treated, labeled DNA from one of the two phages, either in separate vials or together in one vial. The inhomology appears exaggerated with the latter method. Whereas the results of the single- disk experiments show little inhomology between the DNAs, the double-disk experiments show clearly that the DNAs are not completely homologous. In a series of single-disk experiments, the calculated fraction of homology between the DNAs varied from 0.88 to 1.0 . We conclude that the DNAs of phages HP1c1 and S2 are almost, but not totally homologous. It is shown below that the two phages differ in their immunity properties, which also suggests that their DNAs are not completely homologous.

We were unable to obtain sufficient concentrations of defective phage DNA for significant measurements of OD. Amounts of HP1c1 and S2 DNAs readily obtainable were not sufficient to saturate the disks, which is a necessary condition for precise determination of homology with small (unknown) amounts of labeled DNA (4). Consequently, DNA extracted from cells, with or without prophages, was used for most of the hybridization experiments with labeled DNA from defective phage, since these cell DNAs are readily extracted in sufficient amounts.

Some results of such experiments are presented in Table 3, along with comparable results for hybridization between HP1c1 DNA and some of these cell DNAs. One experiment is also shown in which defective phage DNA was incubated with disks containing HP1c1 or S2 DNA. The amount of HP1c1 or S2 DNA on the disks (1 $\mu \mathrm{g})$ is comparable to the amount of phage DNA expected to be present in $100 \mu \mathrm{g}$ of DNA from cells carrying a prophage. The fraction of defective phage DNA annealed with HP1c1 or S2 DNA is negligible. However, there is significant annealing between labeled defective phage DNA and strain $R d \mathrm{DNA}$, and somewhat less annealing with BC200 DNA, from the intact preparation (prepn 1 of Table 3) as well as from the degraded one (prepn 2). The presence of HP1c1 or S2 prophage does not affect the annealing to $R d$ DNA. However, HP1c1 phage DNA does not anneal to $R d$ or BC200 DNA unless there is HP1c1 prophage present. We conclude that the defective phage DNA preparations are not homologous to HP1c1 or S2 DNA, and that the expected homology between the defective phage DNA preparations and strain $R d$, from which the phage was derived, does exist.

The phage preparations also contain DNA homologous to DNA from strain BC200, although the homology is lower than for strain $R d$. There are three possible explanations for this phenomenon. (i) The defective phage preparations were contaminated with bacterial DNA. (ii) The defective phages themselves contain some bacterial DNA. (iii) BC200, though not inducible for defective phage, contains a partial defective 
TABLE 2. Hybridization between HP1c1 and S2 DNAsa

\begin{tabular}{|c|c|c|c|c|c|c|}
\hline \multicolumn{2}{|c|}{$\begin{array}{l}\text { Type and amt of sonically } \\
\text { treated labeled phage DNA }\end{array}$} & \multirow{2}{*}{$\begin{array}{l}\text { Input } \\
\text { (counts/ } \\
\text { min) }\end{array}$} & \multicolumn{2}{|c|}{$\begin{array}{l}\text { Type and amt of } \\
\text { unlabeled disk DNA }\end{array}$} & \multirow{2}{*}{$\begin{array}{c}\text { Percentage of } \\
\text { labeled DNA } \\
\text { annealed }\end{array}$} & \multirow{2}{*}{$\begin{array}{c}\text { Fraction of } \\
\text { homology be- } \\
\text { tween DNAs }\end{array}$} \\
\hline Type & Amt (ug) & & Type & Amt (ug) & & \\
\hline HP1c1 (prepn 1) & 1 & 1,100 & $\begin{array}{l}\text { HP1c1 (prepn 2) } \\
\text { S2 (prepn 2) }\end{array}$ & $\begin{array}{l}10 \\
10\end{array}$ & $\begin{array}{l}48 \\
39\end{array}$ & 0.90 \\
\hline S2 (prepn 1) & 0.2 & 1,400 & $\begin{array}{l}\text { S2 (prepn 3) } \\
\text { HP1c1 (prepn 3) }\end{array}$ & $\begin{array}{r}2 \\
2\end{array}$ & $\begin{array}{l}46 \\
44\end{array}$ & 0.98 \\
\hline HP1c1 (prepn 4) & 0.2 & 1,100 & $\begin{array}{l}\text { HP1c1 (prepn 3) } \\
\text { S2 (prepn 4) }\end{array}$ & $\begin{array}{l}5 \\
5\end{array}$ & $\begin{array}{l}24 \\
12\end{array}$ & \\
\hline S2 (prepn 1) & 0.2 & 1,400 & $\begin{array}{l}\text { S2 (prepn 4) } \\
\text { HP1c1 (prepn 3) }\end{array}$ & $\begin{array}{l}\mathbf{5} \\
\mathbf{5}\end{array}$ & $\begin{array}{l}32 \\
22\end{array}$ & \\
\hline
\end{tabular}

a The first two sets of hybridizations were performed with one disk at a time incubated with labeled DNA. In the last two sets, the disks were incubated with labeled DNA together.

$b$ Calculated as the square root of the ratio of heterologous to homologous fractions annealed (5).

TABLE 3. Hybridization of DNAs from the defective phage and HP1c1 to DNAs from phages HP1c1 and S2 and from strains Rd and BC200 and lysogens of these strains carrying prophages of HP1c1 and S2a

\begin{tabular}{|c|c|c|c|c|c|}
\hline \multicolumn{2}{|c|}{$\begin{array}{l}\text { Type and amt of sonically } \\
\text { treated labeled phage DNA }\end{array}$} & \multirow{2}{*}{$\underset{\text { (counts/min) }}{\text { Input }}$} & \multicolumn{2}{|c|}{ Type and amt of unlabeled disk DNA } & \multirow{2}{*}{$\begin{array}{l}\text { Percentage of } \\
\text { labeled DNA } \\
\text { annealed }\end{array}$} \\
\hline Type & Amt ( $\mu \mathrm{g})$ & & Type & Amt ( $\mu \mathrm{g})$ & \\
\hline $\begin{array}{l}\text { Defective phage } \\
\text { (prepn 1) }\end{array}$ & unknown & 2700 & $\begin{array}{l}\text { HP1c1 } \\
\text { S2 } \\
R d \\
\text { BC200 }\end{array}$ & $\begin{array}{c}1 \\
1 \\
100^{b} \\
100^{b}\end{array}$ & $\begin{array}{l}0.2 \\
0.1 \\
66 \\
12\end{array}$ \\
\hline $\begin{array}{l}\text { Defective phage } \\
\text { (prepn 2) }\end{array}$ & unknown & 2700 & $\begin{array}{l}R d \\
\mathrm{BC} 200 \\
R d(\mathrm{HP} 1 c 1) \\
R d \text { (S2) }\end{array}$ & $\begin{array}{r}100 \\
100 \\
50 \\
50\end{array}$ & $\begin{array}{l}7 \\
3 \\
6 \\
6\end{array}$ \\
\hline $\begin{array}{l}\text { HP1c1 (made from } \\
\text { a lysogen of } \\
\text { BC200) }\end{array}$ & 0.6 & 14,700 & $\begin{array}{l}R d \\
\text { BC200 } \\
\text { BC200 (HP1c1) }\end{array}$ & $\begin{array}{r}100 \\
100 \\
8\end{array}$ & $\begin{array}{l}0.8 \\
0.5 \\
10\end{array}$ \\
\hline
\end{tabular}

a In preparation 1 of defective phage DNA, the phages were treated with DNase before concentration and banding in $\mathrm{CsCl}$. The DNA sedimented normally in a sucrose gradient. In preparation 2 the phages were treated with deoxyribonuclease after banding. Sedimentation of the DNA showed that it was considerably degraded.

${ }^{b}$ Disks incubated with labeled DNA together.

prophage. We have attempted to distinguish between these three possibilities by measuring transformation from various preparations of defective phage DNA from phages induced from antibiotic-resistant variants of strain $R d$, since transformation is a much more sensitive measure of the presence of $H$. influenzae DNA than is radioactive label.

If the amount of hybridization observed is to be accounted for by hypothesis (i) alone, then the amount of transformation should reflect the presence of a substantial fraction of bacterial DNA in the phage DNA preparations that have not been treated with DNase. Furthermore, this bacterial DNA should include all parts of the genome. If hypothesis (ii) is correct, then either a substantial fraction of the phages contains bacterial DNA, or each phage particle contains a large fraction of bacterial DNA. The bacterial DNA could be either a specific region of the host genome or a random selection.

Table 4 shows some of the transformation data for the streptomycin marker obtained from defective phage preparations after they were banded in $\mathrm{CsCl}$ and the DNA was released. It is clear that there is some bacterial DNA present, 
TABLE 4. Transformation with defective phage DNA preparalions of Table 2

\begin{tabular}{l|c|c|c|c}
\hline \multicolumn{1}{c|}{ Prepn } & $\begin{array}{c}\text { No. of streptomycin- } \\
\text { resistant trans- } \\
\text { formants per } \mathrm{ml}\end{array}$ & $\begin{array}{c}\text { A } \\
\text { Equivalent of } \\
\text { bacterial DNA per } \\
\text { ml of phage DNA } \\
\text { prepn }^{a}(\mathrm{\mu g})\end{array}$ & $\begin{array}{c}\text { B } \\
\text { Counts per min } \\
\text { per ml of phage } \\
\text { DNA prepn }\end{array}$ & $\begin{array}{c}\text { Estimated maximum } \\
\text { fraction of bacterial } \\
\text { DNA in phage DNA } \\
\text { prepn }^{b}\end{array}$ \\
\hline 1 & 32 & $5 \times 10^{-5}$ & $1.6 \times 10^{4}$ & 0.003 \\
2 (Before DNase) & 74 & $10^{-4}$ & $5.0 \times 10^{4}$ & 0.002 \\
2 (After DNase) & 0 & 0 & $2.5 \times 10^{4}$ & \\
\hline
\end{tabular}

"Calculated from a calibration curve of the number of transformants per milliliter versus bacterial DNA concentration.

${ }^{b}$ Calculated by multiplying A times $10^{6}$ counts per min per $\mu g$, the maximum specific activity of bacterial DNA obtained under the growth conditions used, and dividing by $B$.

except in preparation 2, after deoxyribonuclease treatment of the banded phage. However, the calculated maximum fraction of bacterial DNA is too small to account for the results of any of the hybridization experiments of Table 3 , unless the bacterial DNA is from a particular region of the chromosome that does not contain the streptomycin marker. We have obtained results similar to those of Table 4 with the erythromycin marker, which is not linked to the streptomycin marker. These data rule out hypothesis (i).

The fact that DNase treatment after $\mathrm{CsCl}$ banding eliminates transformation (Table 4) but not hybridization to $\mathrm{BC} 200$ (Table 3) does not provide a definitive test of hypothesis (ii), since the phages are susceptible to breakage, as judged by the fact that such treatment degrades much of the DNA (Table 3). Therefore we consider that our data do not distinguish between hypotheses (ii) and (iii). However, we consider hypothesis (ii) to be improbable for the following reason. The hybridization data could only be accounted for in terms of hypothesis (ii) if the bacterial DNA packaged by the phage were from a selected region of the chromosome that does not include the streptomycin or erythromycin markers. Phages that package a particular region of the bacterial chromosome are usually a very small fraction of the population (6), whereas there is substantial hybridization of defective phage DNA to BC200 DNA (Table 3). On the other hand, the lack of cohesive ends in defective phage DNA would be expected if each phage contained bacterial DNA at one end of the DNA and phage DNA at the other.

Cross-immunity of HP1cl and S2. The relative plating efficiencies of HP1c1 and S2 phages on strain $R d$ and on strain $R d$ carrying HP1c1 or S2 prophage are given in Table 5 . Whereas both lysogens are immune to the homologous phage, each lysogen is not completely immune to the other phage, although the plating
TABLE 5. Relative plating efficiencies of HP1c1 and S2 phage on $H$. influenzae strain $R d$ and on this strain carrying HP1c1 or S\& prophage

\begin{tabular}{|c|c|c|}
\hline \multirow{2}{*}{ Lawn cells } & \multicolumn{2}{|c|}{ Phage } \\
\hline & HP1c1 & $\mathbf{s 2}$ \\
\hline $\begin{array}{l}R d \\
R d(\mathrm{HP} 1 c 1) \\
R d(\mathrm{~S} 2)\end{array}$ & $\begin{array}{c}1 \\
0 \\
6 \times 10^{-2}\end{array}$ & $2 \times \frac{1}{10^{-4}}$ \\
\hline
\end{tabular}

efficiency of HP1c1 is reduced by more than one order of magnitude on the S2 lysogen, and S2 plating efficiency is reduced even more on the HP1c1 lysogen, suggesting some cross-immunity. S2 phages grown in $R d$ cells or in $R d$ cells lysogenic for HP1c1 show the same reduced plating efficiency on HP1c1 lysogens. Therefore, a restriction-modification system cannot explain the reduced plating efficiency.

\section{DISCUSSION}

The morphologies of HP1c1, S2, and the defective phage are very similar. The defective phage, however, seems to exhibit an altered tail plate-fiber assembly, which could possibly account for the lack of attachment of this phage to the bacterial cell. The lack of cohesive ends in defective phage DNA may be another reason why no host has been found for this phage.

The DNA of the defective phage shows little or no homology with that of the other two phages, although it is approximately the same size. Thus very different nucleotide sequences can code for structures that are almost indistinguishable in gross morphology.

Although there is a high degree of homology between HP1c1 and S2 DNAs, the repressors coded for by the two phages, or the regions of the DNA that bind the repressor, must be differ- 
ent, since it is possible to grow one phage on the lysogen of the other. However, it is likely that the two immunity systems are to some extent similar, since the plating efficiencies of the phages are drastically reduced on the nonhomologous lysogens.

\section{ACKNOWLEDGMENTS}

We thank Barbara Hamkalo, Karen Hart, and Salil Niyogi for helpful comments on the manuscript.

This research was sponsored by the U.S. Atomic Energy Commission under contract with the Union Carbide Corporation.

\section{LITERATURE CITED}

1. Barnhart, B. J., and S. H. Cox. 1968. Radiationsensitive and radiation-resistant mutants of Haemophilus influenzae. J. Bacteriol. 96:280282.

2. Barnhart, B. J., and S. H. Cox. 1970. Recovery of Haemophilus influenzae from ultraviolet and $\mathrm{X}$-ray damage. Photochem. Photobiol. 11:147162.

3. Bendler, J. W., and S. H. Goodgal. 1968. Prophage S2 mutants in Haemophilus influenzae: a technique for their production and isolation. Science 168:464-465.

4. Boling, M. E. 1972. Homology between the deoxyribonucleic acids of Haemophilus influenzae and Haemophilus parainfluenzae. J. Bacteriol. 118:745-750.
5. Boling, M. E., J. K. Setlow, and D. P. Allison. 1972. Bacteriophage of Haemophilus influenzae. I. Differences between infection by whole phage, extracted phage DNA and prophage DNA extracted from lysogenic cells. J. Mol. Biol. 63:335348.

6. Campbell, A. 1971. Genetic structure, p. 13-44. In A. D. Hershey (ed.), The bacteriophage lambda. Cold Spring Harbor Laboratory, Cold Spring Harbor, N.Y.

7. Caro, L. G., and M. Schnös. 1966. The attachment of the male-specific bacteriophage F1 to sensitive struins of Escherichia coli. Proc. Nat. Acad. Sci. U.S.A. 56:126-132.

8. Carrier, W. L., and R. B. Setlow. 1971. Paper strip method for assaying gradient fractions containing radioactive macromolecules. Anal. Biochem. 43:427-432.

9. Harm, W., and C. S. Rupert. 1963. Infection of transformable cells of Haemophilus influenzae by bacteriophage and bacteriophage DNA. Vererbungsl. 94:336-348.

10. Samuels, J., and J. K. Clarke. 1969. New bacteriophage of Haemophilus influenzae. J. Virol. 4:797-798.

11. Setlow, J. K., D. C. Brown, M. E. Boling, A. Mattingly, and M. P. Gordon. 1968. Repair of deoxyribonucleic acid in Haemophilus influenzas I. X-ray sensitivity of ultraviolet-irradiated bacteriophage and transforming deoxyribonucleic acid. J. Bacteriol. 95:546-558.

12. Stachura, I., F. W. McKinley, G. Leidy, and H. Alexander. 1969. Incomplete bacteriophage-like particles in ultraviolet-irradiated Haemophilus. J. Bacteriol. 98:818-820. 